\title{
Characterization of Polydiphenylamine Electrochemically Synthesized by Spectroscopic and Thermal Techniques
}

\author{
Henrique de Santana, ${ }^{\dagger}$ Jivaldo do Rosário Matos, and Márcia Laudelina Arruda Temperini ${ }^{\dagger \dagger}$ \\ Departamento de Química Fundamental, Instituto de Quimica, Universidade de São Paulo, \\ Cx.P. 26077, CEP 05599-970 São Paulo, SP, Brazil
}

(Received September 16, 1997)

\begin{abstract}
Two kinds of films, named A and B, of polydiphenylamine (PDPA) electrochemically synthesized have been characterized by ex situ resonance Raman, FT-IR and UV-Vis-NIR Reflectance spectroscopies. The ex situ RR spectra of the films showed differences, that were rationalized assuming the predominance of the diphenosemiquinone aminoimine structure in the film A, while in the film B the diphenoquinone diimine segments were predominant. The variation of the nature of the film adsorbed on the electrode with the applied potential has been monitored by means of the in situ resonance Raman technique. The bands characteristics of the diphenosemiquinone aminoimine moiety are dependent on the laser power employed, being converted to diphenoquinone diimine and diphenyl diamine segments. This result was confirmed by FT-IR spectra of the film A after heating. The thermal behavior of the films was monitored by thermogravimetry (TG), derivative thermogravimetry (DTG), and differential scanning calorimetry (DSC).
\end{abstract}

KEY WORDS Polydiphenylamine / Resonance Raman / Thermal Behavior /

Raman spectroscopy has been extremely useful in the structural characterization of conducting polymers. ${ }^{1}$ Polyaniline is one of the best conducting polymer investigated by vibrational spectroscopy. By means of resonance Raman spectroscopy it was possible to understand the nature of the chromophoric species and the relationships between structure and conductivity in this polymer. ${ }^{2-4}$ The resonance Raman spectroelectrochemical study of polyaniline selectively deuterated in the ring or in the nitrogen allowed a consistent normal coordinate analysis of this polymer to be performed. ${ }^{5}$

In order to increase the thermal and oxidation stability of polyaniline without degradation of its conductivity, incorporation of substituents in the rings or modification of its chains are strategies that have been used. ${ }^{6}$ This is the case of polydiphenylamine (PDPA) which has been substantially less studied than polyaniline.

The first study of PDPA focused on the details of its chemical preparation and thermal stability, ${ }^{7}$ as well as on its ability to inhibit the thermooxidative damage of different polymers. ${ }^{8}$ It is well known that PDPA can also be electrochemically synthesized from the monomer by a 4,4' C-C phenyl-phenyl coupling mechanism leading to a structure with alternating amine and $p$-diphenylene units. ${ }^{9,10}$ Concerning its characterization the ex situ IR technique was the most employed aiming at the determination of the type and degree of polymerization. ${ }^{10,11}$ Guay et al. have studied the electrochromic properties of PDPA and rationalized their in situ UVVis results and FT-IR measurements in terms of the presence of polarons and biporalons. ${ }^{12}$ Recently, Chan et al. synthesized poly(4-aminobiphenyl) both chemically and electrochemically and compared their properties using various techniques. ${ }^{13}$

The first stages of the electrochemical oxidation of diphenylamine (DPA) have been monitored by in situ resonance Raman and reflectance spectroscopies. ${ }^{14}$ In that previous work it was confirmed that the dimer formed was $N, N^{\prime}$-diphenylbenzidine (DPB), Figure 1, and the characteristic vibrational bands of the diphenylbenzidine radical cation $\left(\mathrm{DBP}^{+} \cdot\right)$ and dication $\left(\mathrm{DPB}^{2+}\right)$, Figure 1 were assigned. The resonance Raman effect of each species and the experimental conditions for the interconvertion between the diphenosemiquinone aminoimine and the diphenoquinone diimine structures in the dimer were determined.

Nevertheless, a spectroscopic characterization and stability study of the diphenosemiquinone aminoimine and diphenoquinone diimine segments in the PDPA backbone is not available in the literature. In the present work two kinds of PDPA films have been characterized
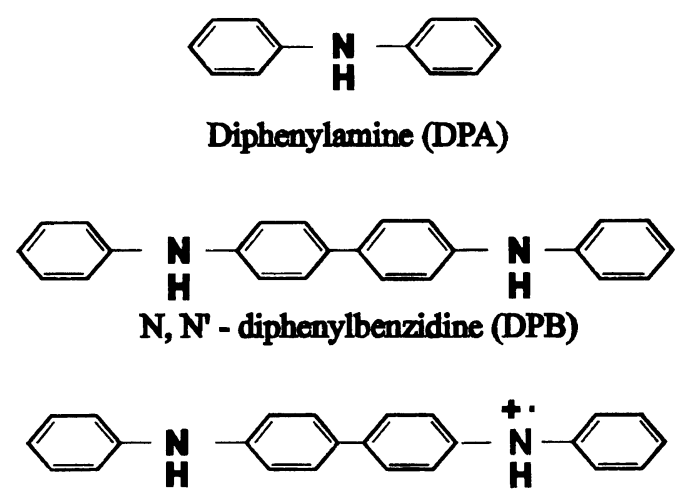

$\mathbf{N}, \mathbf{N}$ - diphenylbenridine radical cation (DPB ${ }^{+}$)

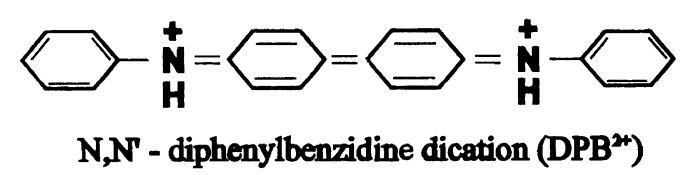

Figure 1. Schematic structure of the monomer, dimer, and its radical cation and dication.

\footnotetext{
† Permanent address: Universidade Estadual de Londrina, Paraná, Brazil.

${ }^{+\dagger}$ To whom correspondence should be addressed.
} 

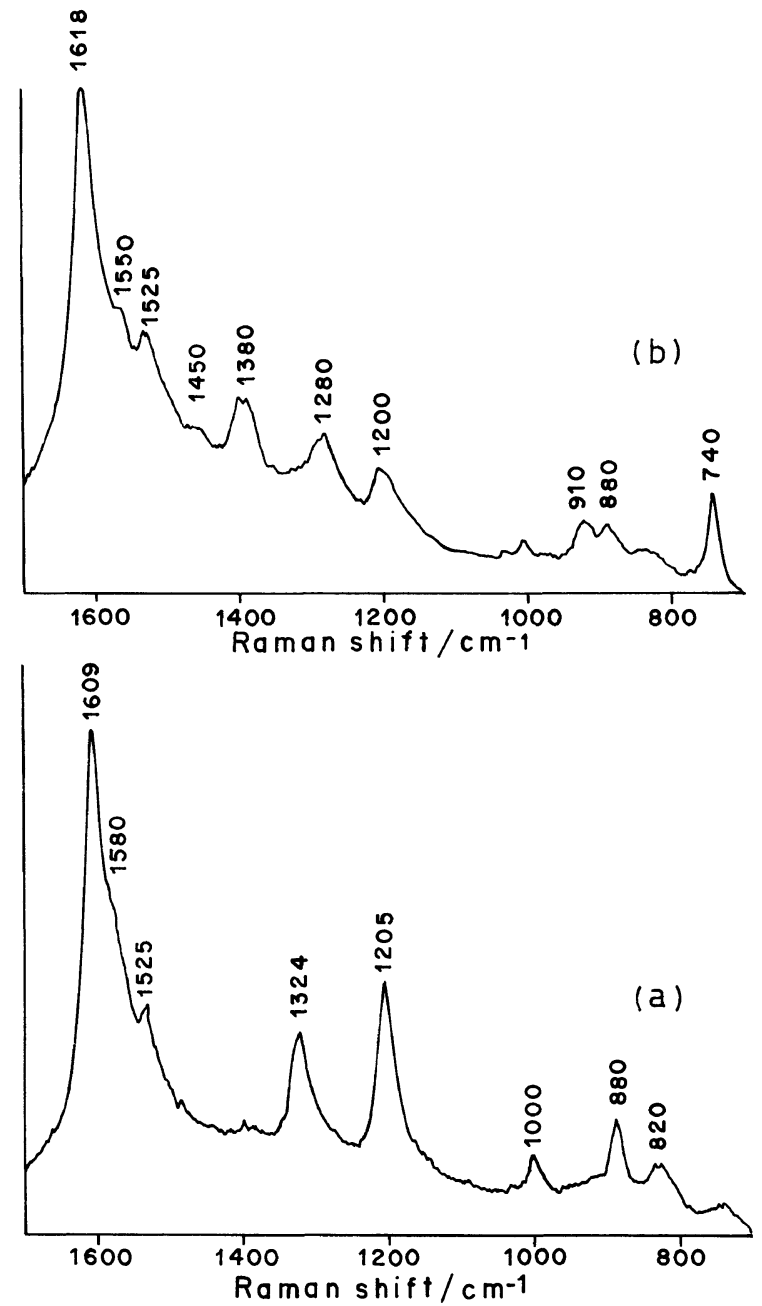

Figure 2. Ex situ resonance Raman spectra of: (a), polymeric film A; (b), polymeric film $\mathrm{B}\left(\lambda_{0}=514.5 \mathrm{~nm}\right)$.

by ex situ resonance Raman, FT-IR and reflectance techniques, aiming at the identification of these segments in the polymeric films. The dependence of the nature of PDPA film adsorbed on an electrode on the applied potential was monitored by in situ resonance Raman spectroscopy. The effect of the laser power on the Raman spectra of the films was also examined. The thermal behavior of the PDPA films was monitored by FT-IR spectroscopy and TG/DTG and DSC techniques.

\section{EXPERIMENTAL}

Diphenylamine (Merck) was purified by double recrystallization from petroleum ether. Acetonitrile (Merck) and tetraethylammonium tetrafluoroborate, $\mathrm{Et}_{4} \mathrm{NBF}_{4}$, (Aldrich) were used as received.

Electropolymerization was performed in a single compartment cell fitted with $1.0 \mathrm{~cm}^{2} \mathrm{Pt}(99.99 \%)$ plate as working electrode, a large $\mathrm{Pt}$ sheet as auxiliary electrode and a saturated calomel electrode (SCE) as the reference electrode. The electrolyte solution was $0.1 \mathrm{M}$ DPA and $0.1 \mathrm{M} \mathrm{Et}_{4} \mathrm{NBF}_{4}$ in deaerated acetonitrile. The polymerization of DPA was carried out by continuous cycling the potential between 0.0 and $1.5 \mathrm{~V}$ until a charge of $25 \mathrm{C} \mathrm{cm}^{-2}$ was reached. The polymer synthesized on the electrode surface was obtained in two forms: i) the film A obtained by taking the working electrode out from

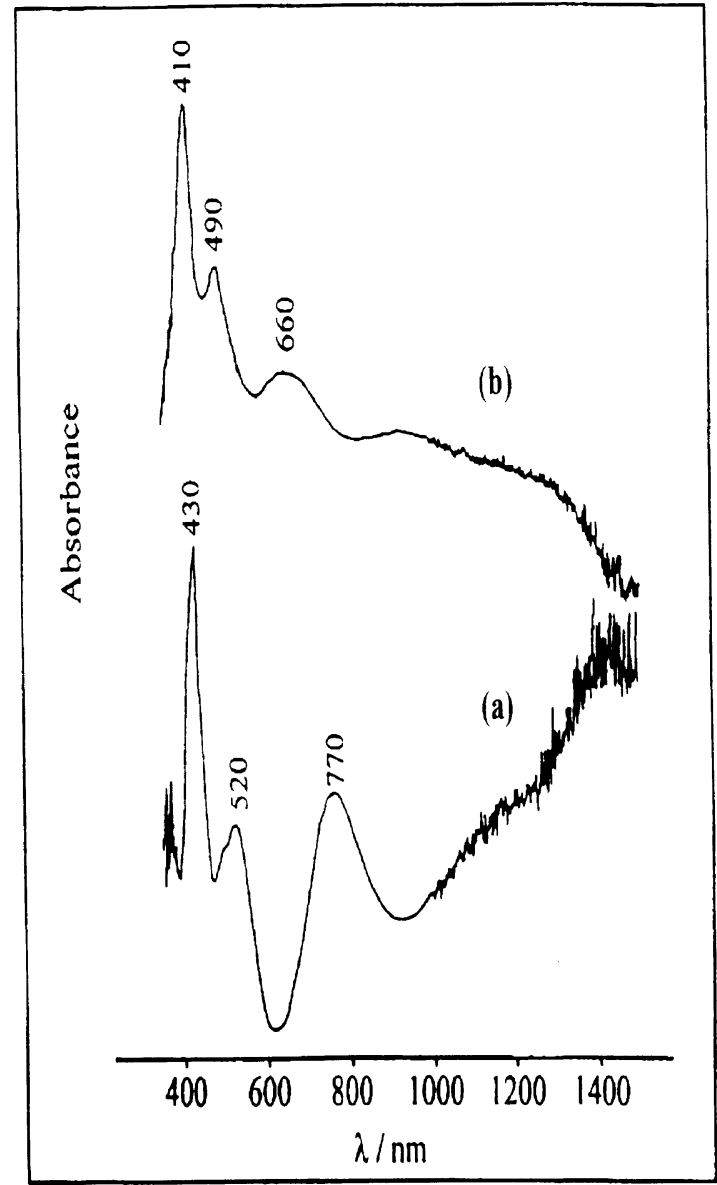

Figure 3. Ex situ reflectance spectra of: (a), polymeric film A; (b), polymeric film B.

the cell at $1.0 \mathrm{~V}$ and ii) the film $\mathrm{B}$ obtained by holding the electrode potential at $0.0 \mathrm{~V}$ for approximately $30 \mathrm{~min}$, during which the reducing current was reduced to zero. The as-synthesized polymer films were purified with acetonitrile in a Soxhlet device for about $1 \mathrm{~h}$, to remove the excess of electrolytes. The polymers were dried in vacuum for $12 \mathrm{~h}$.

The electrochemical equipment was a potentiostatgalvanostat PAR 273 EG\&G connected to a HP7090A system.

Thermogravimetric (TG) and derivative thermogravimetric (DTG) curves were obtained with a thermobalance model TGA 50 (Shimadzu), using platinum crucibles with ca. $2 \mathrm{mg}$ of the sample, under dynamic air atmosphere

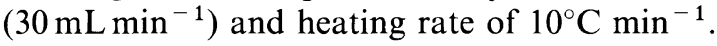

Differential scanning calorimetry (DSC) curves were obtained with DSC 25 cell from Mettler system TA 4000 Series using aluminium crucibles with $c a .2 \mathrm{mg}$ of the sample, under dynamic nitrogen atmosphere $(50 \mathrm{~mL}$ $\min ^{-1}$ ) and heating rates of 20 or $10^{\circ} \mathrm{C} \mathrm{min}^{-1}$.

The Raman spectra were acquired on a Spex Triplemate-1877 fitted with an OMA-III multichannel detection system. The excitation wavelength was the $514.5 \mathrm{~nm} \mathrm{Ar}^{+}$laser line with $30 \mathrm{~mW}$ at the sample. The scattered light was detected perpendicular to the laser beam and the spectral slit width was $10 \mathrm{~cm}^{-1}$. The spectroelectrochemical cell used for in situ RR experiments has been described elsewhere. ${ }^{15}$

The IR spectra were recorded on a Bomen DA 3.16 
using pressed $\mathrm{KBr}$ disks. To study the effect of temperature on the polymeric films by IR spectroscopy, a $\mathrm{KBr}$ disk of the sample was placed into a furnace and heated for $c a .30 \mathrm{~min}$ at the desired temperature. The hot sample was allowed to cool inside a desiccator and the spectrum was obtained at room temperature.

The ex situ reflectance spectra of film A and B adsorbed on ITO electrodes were obtained on a Guided Wave (model 260) spectrometer equipped with a silicongermanium detector, coupled to a personal computer. The background was the spectrum of the bare ITO electrode.

\section{RESULTS AND DISCUSSION}

Figure 2 shows the ex situ Raman spectra of the films $\mathrm{A}$ and $\mathrm{B}$ excited with the $514.5 \mathrm{~nm}$ wavelength. As can be seen in the ex situ reflectance spectra of film A and B, Figure 3, this excitation wavelength is within the absorption region of the films and so provides the resonance Raman condition.

Comparing the wavenumbers of the spectra, shown in Figure 2, with those of the DPB and its radical cation and dication, presented in Table I, it can be seen that the frequencies are very similar and consequently they

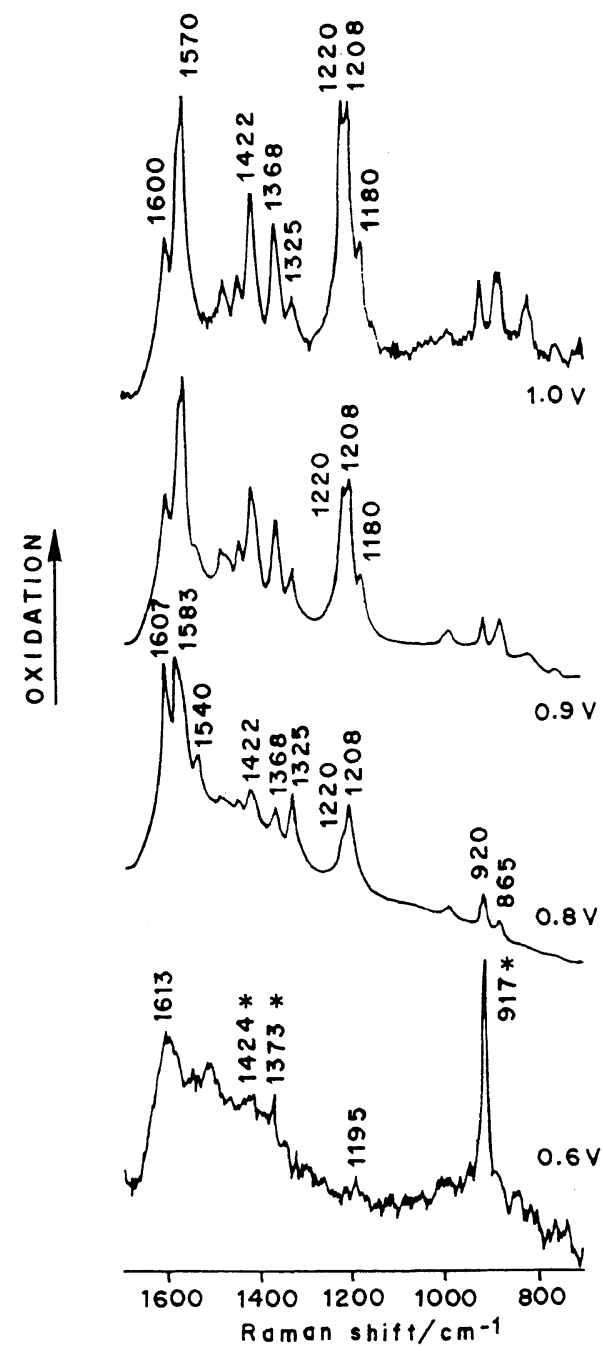

can be used for analyzing the polymer spectra; also the inter-ring vibrational mode can be selected as one of the best band to characterize the presence of diphenyl diamine (Figure 1, DPB), diphenosemiquinone aminoimine (Figure $1, \mathrm{DPB}^{+} \cdot$ ) and diphenoquinone diimine (Figure 1, $\mathrm{DPB}^{2+}$ ) segments in the PDPA films. The bands at 1380 and $1280 \mathrm{~cm}^{-1}$, assigned to the inter ring $\mathrm{C}-\mathrm{C}$ stretching of the diphenoquinone and diphenyl structures, respectively, were only observed in the spectrum of film B. In the spectrum of film $A$ the band

Table I. Characteristic Raman frequencies of $N, N^{\prime}$-diphenylbenzidine (DPB) and its radical cation and dication ${ }^{14}$

\begin{tabular}{lccc}
\hline & \multicolumn{3}{c}{${\text { Raman frequencies } / \mathrm{cm}^{-1}}^{\text {Assignment }}{ }^{\mathrm{a}}$} \\
\cline { 2 - 4 } & $\mathrm{DPB}$ & $\mathrm{DPB}^{+}$ & $\mathrm{DPB}^{2+}$ \\
\hline Ring $v \mathrm{C}-\mathrm{C}$ & $1610(10)$ & $1607(10)$ & - \\
Ring $v \mathrm{C}-\mathrm{C}$ & $1591(\mathrm{sh})$ & $1582(8.5)$ & $1572(10)$ \\
$\nu \mathrm{C}-\mathrm{N}$ & $1238(1.0)$ & $1538(4.2)$ & $1416(7.0)$ \\
Inter ring $v \mathrm{C}-\mathrm{C}$ & $1285(2.8)$ & $1329(5.6)$ & $1362(5.0)$ \\
$\beta \mathrm{C}-\mathrm{H}$ & $1200(2.2)$ & $1205(5.3)$ & $1218(7.0)$ \\
$\beta \mathrm{C}-\mathrm{H}$ & - & - & $1204(7.0)$ \\
$\beta \mathrm{C}-\mathrm{H}$ & - & - & $1177(5.4)$
\end{tabular}

a Approximate description; relative intensities in parenthesis.
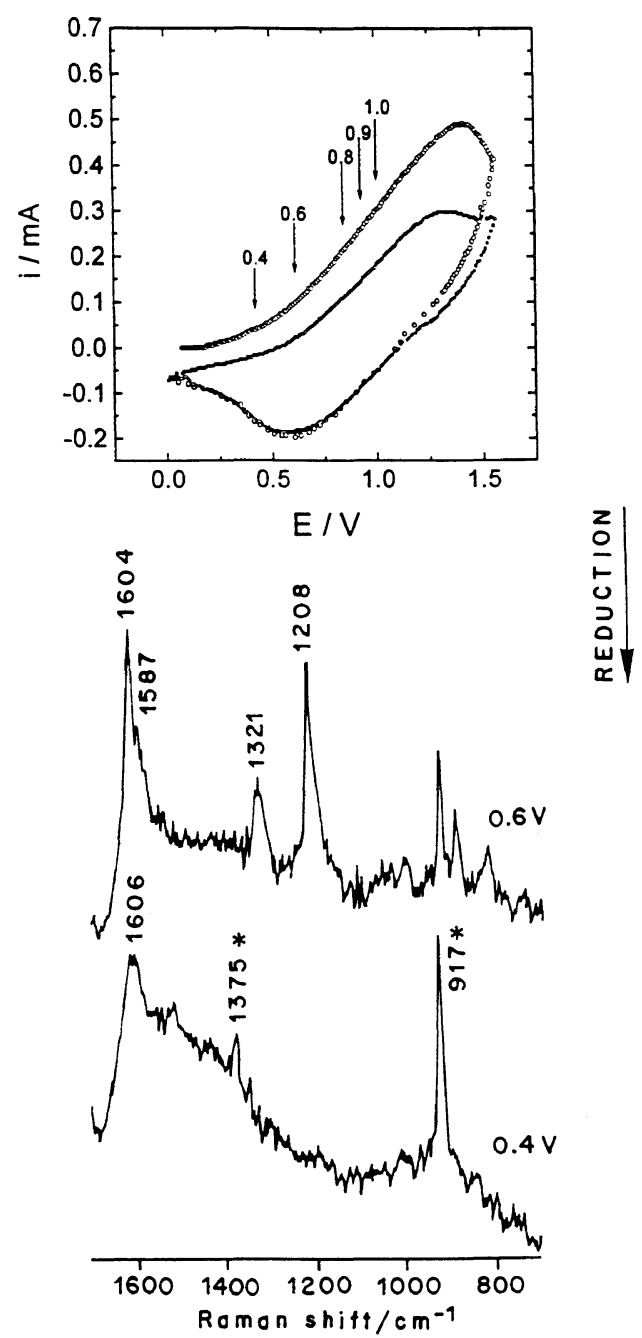

Figure 4. In situ resonance Raman spectra of a polymeric film adsorbed on a platinum electrode in $0.1 \mathrm{M} \mathrm{Et}_{4} \mathrm{NBF}_{4}+\mathrm{H}_{3} \mathrm{CCN}_{\mathrm{N}}$ for the applied potentials indicated in the Figure, $\lambda_{0}=514.5 \mathrm{~nm}$, with a power $c a .30 \mathrm{~mW}$. ${ }^{*}$ Solvent bands. The insert shows the voltammograms of a polymeric films where the arrows indicate the potentials where the spectra were obtained. 



Figure 5. Ex situ resonance Raman spectra of the film $\mathrm{A}$ as a function of the exposure time. $\lambda_{0}=514.5 \mathrm{~nm}$ with a power of: (a), $30 \mathrm{~mW}$; (b), $80 \mathrm{~mW}$; (c), $300 \mathrm{~mW}$.

at $1324 \mathrm{~cm}^{-1}$ was assigned to the same vibrational mode but for the diphenosemiquinone structures. This result shows that in the film $B$ there is a predominance of diphenoquinone and diphenyl type rings while in the backbone of the film A there is more diphenosemiquinone rings. This result is confirmed by the ex situ reflectance spectra of film A and B (Figure 3 ) since the absorptions in the $1000-1400 \mathrm{~nm}(1.24-0.88 \mathrm{eV})$ region are characteristic of free-carrier excitation. ${ }^{16,17}$ The strong increase of the background in this region in the spectrum of film $\mathrm{A}$ in comparison with that of the film $\mathrm{B}$, is an indication of the higher concentration of diphenosemiquinone rings in the film $\mathrm{A}$.

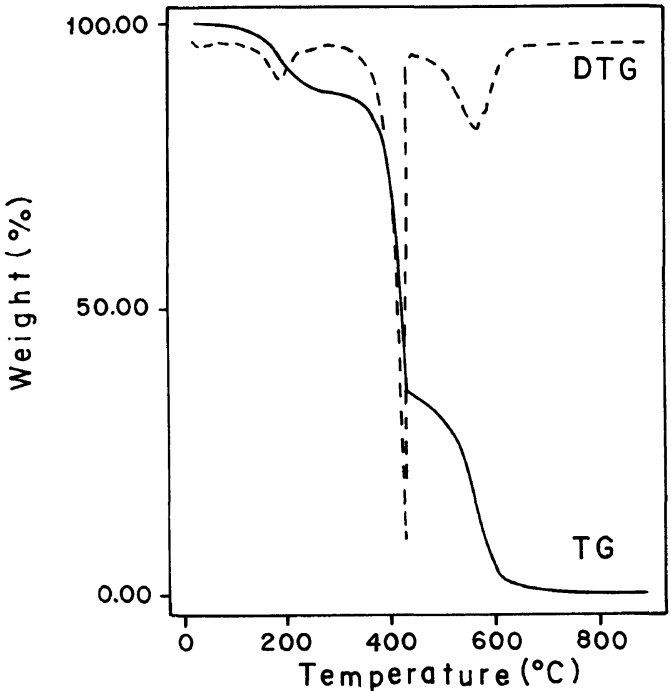

(b)

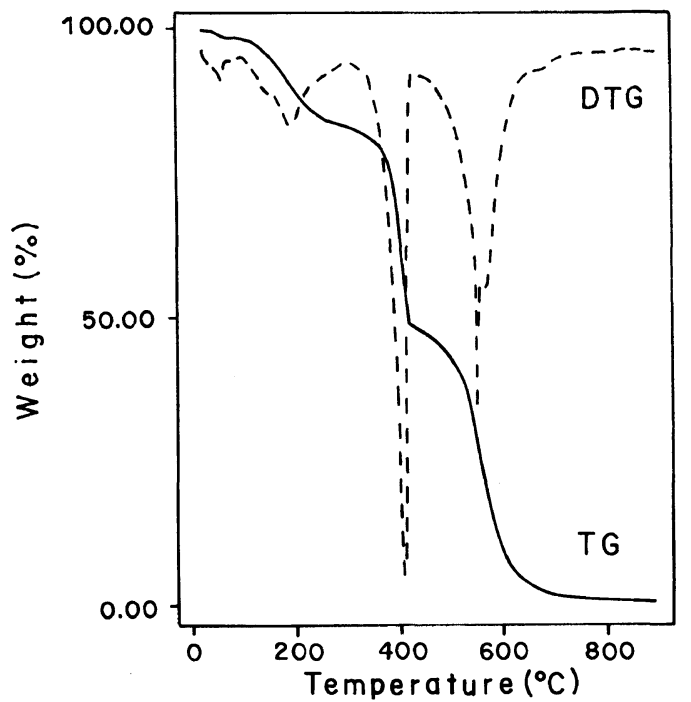

(a)

Figure 6. TG/DTG curves in dynamic air atmosphere and heating rate of $10 \mathrm{~K} \mathrm{~min}^{-1}$. (a), film A; (b), film B.

Another indication of the higher oxidation state of the film B when compared to film A is the assymmetry of the $1200 \mathrm{~cm}^{-1}$ band $(\beta \mathrm{C}-\mathrm{H})$ in the resonance Raman spectrum of film B (Figure 2). The reason is that in the in situ resonance Raman spectrum of the oxidized dimer $\left(\mathrm{DPB}^{2+}\right)$ there are three bands at 1218,1204 , and $1177 \mathrm{~cm}^{-1}$ while in the radical cation dimer $\left(\mathrm{DPB}^{+\cdot}\right)$ only one band is observed at $1205 \mathrm{~cm}^{-1}$ (see Table I). The asymmetry of the $1200 \mathrm{~cm}^{-1}$ band could thus result from the overlapping of the bands at lower wavenumbers.

Figure 4 shows the in situ resonance Raman spectra of a PDPA film adsorbed on a platinum electrode in a $0.1 \mathrm{M} \mathrm{Et}_{4} \mathrm{NBF}_{4}$ acetonitrile solution. The insert is a typical voltammograms of a polymeric film showing the potentials where the spectra were taken. During the positive scan, at less positive potentials $(0.6 \mathrm{~V})$ the strongest bands are due to the solvent and only weak features at 1613 (C-C stretching mode in diphenoic type rings) and $1195 \mathrm{~cm}^{-1}(\mathrm{C}-\mathrm{H}$ in-plane bending in the same type of ring) are from the polymer. At $0.8 \mathrm{~V}$ bands of the polymer are enhanced and the 1208, 1325, 1540 , and $1607 \mathrm{~cm}^{-1}$ bands of the diphenosemiquinone aminoimine structures and also the 1220 (shoulder at 



TEMPERATURE $\left({ }^{\circ} \mathrm{C}\right)$

Figure 7. DSC curves in dynamic $\mathrm{N}_{2}$ atmosphere and heating rate of $20 \mathrm{Kmin}^{-1}$ : (a), film A; (b), film B. DSC curves of the film A in the temperature range of $20-90^{\circ} \mathrm{C}$ in dynamic $\mathrm{N}_{2}$ atmosphere and heating rate of $10 \mathrm{~K} \mathrm{~min}^{-1}$ : (c), first heating; (d), second heating.

this potential), 1368,1422 , and $1583 \mathrm{~cm}^{-1}$ bands of diphenoquinone diimine segments are observed. At $1.0 \mathrm{~V}$ the characteristics bands of diphenoquinone structures at $1180,1220 \mathrm{~cm}^{-1}$ (C-H in-plane bending), 1368 (interring $\mathrm{C}-\mathrm{C}$ stretching), 1422 (ring $\mathrm{C}-\mathrm{N}$ stretching), and $1570 \mathrm{~cm}^{-1}(\mathrm{C}-\mathrm{C}$ ring stretching) predominate. During the reduction, at $0.6 \mathrm{~V}$ the spectrum presents the strongest bands at 1208,1321 , and $1604 \mathrm{~cm}^{-1}$ characteristic of the diphenosemiquinone aminoimine segments. The spectrum bleaches completely during further reduction $(0.4 \mathrm{~V})$. These results are very similar with those obtained by Lapkowski et al. for polyaniline in acetonitrile solution. ${ }^{18}$

Comparing the ex situ Raman spectra of films A and B, Figure 2, to the in situ Raman spectra in Figure 4, some information about the stability of the structures in the films can be obtained. The film B was formed when the synthesis was terminated in a reduction region of the potential. At this region, the in situ spectra showed only bands of the diphenosemiquinone aminoimine and/or diphenyl diamine structures. Nevertheless, the ex situ spectrum of film B showed bands characteristic of the diphenoquinone diimine structures. This difference could be explained considering that the sample was probably oxidized when exposed to the atmosphere. This effect has already been observed in reduced samples of polyaniline by Kuzmany et al. ${ }^{2}$ As already mentioned the synthesis of film A is accomplished when the potential reaches $1.0 \mathrm{~V}$. In its ex situ Raman spectrum the most proeminent bands were due to the diphenosemiquinone aminoimine structure while the in situ Raman spectrum at $1.0 \mathrm{~V}$ showed bands characteristic of diphenoquinone diimine structures. This result is explained considering that, after disconnecting the electrode, the protonated diphenoquinone diimine structures are converted to diphenosemiquinone diaminoimine structures in the polymeric matrix, through an internal oxidation-reduction reaction. ${ }^{19}$

Figure 5a shows time dependence of the Raman spectra of film A excited by $30 \mathrm{~mW}$ with the $514.5 \mathrm{~nm}$ line. No spectral changes were observed and these spectra are characteristic of a polymeric film with high concentration of diphenosemiquinone structures. As the power of the laser excitation is increased $(80 \mathrm{~mW})$, Figure $5 \mathrm{~b}$, the broadening of the bands at 1205 and $1320 \mathrm{~cm}^{-1}$ and the appearance of the weak features at $1380 \mathrm{~cm}^{-1}$ indicates the formation of diphenoquinone like structures. The intensity of the band at $1380 \mathrm{~cm}^{-1}$ has a little increase with time and simultaneously the intensities of the bands at 1320 and $885 \mathrm{~cm}^{-1}$ decrease; a shoulder at $1280 \mathrm{~cm}^{-1}$ is also observed. For high laser power, $c a$. $300 \mathrm{~mW}$, (Figure 5c) the same changes occur and the observation of the bands at 1380 and $1280 \mathrm{~cm}^{-1}$ confirms the formation of diphenoquinone and diphenyl structures. So the increase of the laser power for the $514.5 \mathrm{~nm}$ excitation wavelength induces a conversion of diphenosemiquinone aminoimine units into diphenoquinone diimine and diphenyl diamine segments.

The thermal behavior of the films A and B was evaluated using the TG/DTG and DSC techniques.

Figure 6 presents the TG/DTG curves of the samples. For film A, the TG curve shows a four step weight-loss process with DTG peaks at $62,190,410,550$, and a shoulder at $570^{\circ} \mathrm{C}$, having a percentage of weight-loss of $1.8,14.9,35.3$, and 46.6 respectively. In the film B the TG curve also shows a four step weight-loss process with DTG peaks at $42,200,430,570$, and a shoulder at $600^{\circ} \mathrm{C}$ but the percentage of weight-loss are not the same as for film A probably because the slightly different composition of the films.

Figure 7 shows the DSC curves of the films A and B. The assymmetry presented by the first peak at $63.5^{\circ} \mathrm{C}$ in the DSC curve of film A, Figure 7a, may indicate that more than one thermal event is occuring. In order to prove this supposition another DSC curve, with a lower heating rate and with a higher amount of substance was obtained. This DSC curve is presented in Figure $7 \mathrm{c}$ and two peaks are observed at 30 and $68^{\circ} \mathrm{C}$. In order to assign these peaks, the film A was re-heated and the second run gave the curve in Figure 7d. Since the first peak was not 


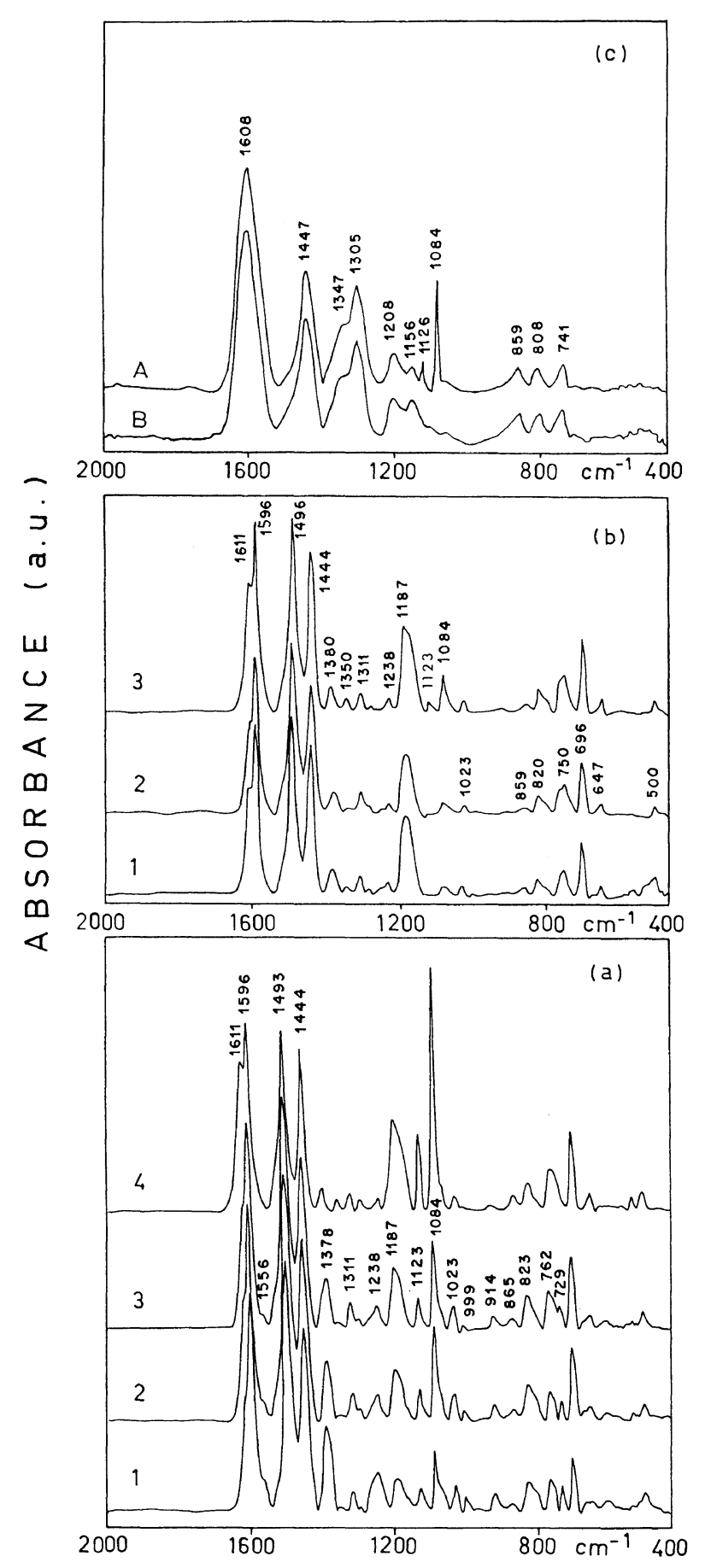

Figure 8. Room temperature FT-IR spectra: (a), spectra of the film A; 1 , film without thermal treatment; 2 , after heating the film up to $100^{\circ} \mathrm{C} ; 3$, after heating up to $170^{\circ} \mathrm{C} ; 4$, after heating up to $400^{\circ} \mathrm{C}$; (b), spectra of the film B; 1 , film without heating treatment; 2 , after heating the film up to $170^{\circ} \mathrm{C} ; 3$, after heating up to $400^{\circ} \mathrm{C}$; (c), spectra of the films $\mathrm{A}$ and $\mathrm{B}$ after heating the films up to $600^{\circ} \mathrm{C}$.

observed in the curve of Figure $7 \mathrm{~d}$ it was attributed to an elimination of volatiles and/or a relaxation of the polymeric chains in the film. The second peak at $72^{\circ} \mathrm{C}$, which is observed during the two heating runs, can be assigned to a phase transition in the PDPA film.

The very weak peak at $200^{\circ} \mathrm{C}$ in the DSC curves of the films A and $\mathrm{B}$ can be correlated to the second weight-loss process in the TG curves of the films. It can be assigned to the sublimation of low-molecular weight fraction existing in the polymeric matrix since the per- centage of weight-loss in this event is equal to the percentage of dimer and trimer obtained by gel permeation chromatographic analysis of film A.

The exothermic peaks between 380 and $500^{\circ} \mathrm{C}$ in the DSC curves of the films A and B correspond in the TG curves to the third process with a weight-loss of 35 and $53 \%$, respectively. This process can be assigned to the polymer degradation. This assignment is in agreement with the gel permeation chromatographic analysis of film A which gave $38 \%$ of higher oligomeric fraction (hexamer and undecamer).

The fourth step, above $500^{\circ} \mathrm{C}$ in the TG curves of films A and B with 46.6 and $34.2 \%$ of weight-loss, respectively, can be attributed to the thermal decomposition of the electrolyte salt present in the polymeric matrix and to the burning of the elemental carbon formed in the third step. This assignment is also in agreement with the gel permeation chromatographic analysis of film A which gave a $40 \%$ of electrolyte salt in the polymeric mass.

Figures $8 \mathrm{a}$ and $8 \mathrm{~b}$ present the FT-IR spectra at room temperature of the film $\mathrm{A}$ and $\mathrm{B}$ as $\mathrm{KBr}$ pellets without (bottom spectra) and with a thermal treatment. Figure $8 \mathrm{c}$ presents the room temperature spectra after heating the $\mathrm{KBr}$ pellets until $600^{\circ} \mathrm{C}$.

The IR spectra of films $\mathrm{A}$ and $\mathrm{B}$ without thermal treatment (bottom spectra of Figures $8 \mathrm{a}$ and $8 \mathrm{~b}$, respectively) are different, reflecting the difference in the amount of diphenoquinone diimine and diphenosemiquinone aminoimine structure in each film. The bands at $1556,1378,1311$, and $1238 \mathrm{~cm}^{-1}$ are higher in the spectrum of film A than in that of film B. Since our Raman results indicate that film A possesses more diphenosemiquinone aminoimine segments one can tentatively assign these bands to such moiety. The band at $1187 \mathrm{~cm}^{-1}$ which presents a low relative intensity in the spectrum of film A (spectrum 1, Figure 8a) and medium intensity in the spectrum of film B (spectrum 1, Figure $8 \mathrm{~b}$ ), can be tentatively assigned to the diphenoquinone $\mathrm{C}-\mathrm{H}$ bending vibration.

It must be noted that the relative intensities of the bands at 1084 and $1123 \mathrm{~cm}^{-1}$ due to the electrolyte salt $\left(\mathrm{Et}_{4} \mathrm{NBF}_{4}\right)$ are higher in the spectrum of film $\mathrm{A}$; this was expected since the film $\mathrm{A}$ was removed of the electrochemical cell at a more positive potential than the film B. This result is in agreement with the percentages of weight-loss in the fourth process in the TG curves of films $\mathrm{A}$ and $\mathrm{B}$, which is greater in the curve of film $\mathrm{A}$.

Comparing the IR spectra of the film B submitted to thermal treatment between 170 and $400^{\circ} \mathrm{C}$, with the spectrum of the film without treatment (Figure $8 \mathrm{~b}$ ) no marked differences can be noted. Only the increase in the relative intensities of the bands due to the electrolyte at 1084 and $1123 \mathrm{~cm}^{-1}$ is observed. This result is due to the loss of the polymeric mass when the temperature is increased. The increase in the relative intensities of the bands due to the electrolyte salt was also observed in the spectra of the film A after the thermal treatment (Figure $8 \mathrm{a}$ ). Nevertheless the heating of the film $\mathrm{A}$ induces a change in the relative intensities of the polymer bands. As the temperature is increased, the relative intensities of the bands at 1378,1311 , and $1238 \mathrm{~cm}^{-1}$ decrease, the band at $1556 \mathrm{~cm}^{-1}$ disappears and the relative intensity of the band at $1187 \mathrm{~cm}^{-1}$ increases. It is noteworthy 
that the spectra of films A and B after heating to $400^{\circ} \mathrm{C}$ are very similar, disregarding the bands of the electrolyte, that are already present in the room temperature spectrum of film A. So it can be suggested that in the chains of film A there is a conversion of diphenosemiquinone aminoimine segments into diphenoquinone diimine and diphenyl diamine structures with the increase in the temperature. The thermal conversion of polarons into bipolarons has already been observed in poly( $p$-phenylenevinylene). ${ }^{20}$

The IR spectra of the films A and B after heating to $600^{\circ} \mathrm{C}$ are very different from those of the films without thermal treatment, indicating their degradation. The apparent disagreement between the observation of the characteristic spectra of the polymers after heating to $400^{\circ} \mathrm{C}$ and the value of $410^{\circ} \mathrm{C}$ for the degradationtemperature of the polymers in the TG/DTG curves is due to the procedure adopted in the case of the IR spectra. In the $\mathrm{KBr}$ pellets some of the polymeric mass can be stable above its degradation temperature due to the effect of the $\mathrm{KBr}$ matrix.

\section{CONCLUSION}

The results indicate that the nature of the adsorbed film is a function of the potential where the electrochemical synthesis is terminated. Comparing the in situ and ex situ spectra of the polymers it was possible to infer about the stability of the charged segments in the polymeric matrix. For the $514.5 \mathrm{~nm}$ excitation radiation, the laser power induces the conversion of diphenosemiquinone aminoimine structures to diphenoquinone diimine and diphenyl diamine segments. The same reaction is also induced by thermal treatment.

Acknowledgments. This work was supported by FAPESP and BID/USP. M.L.A.T. and H. de S. are indebted to $\mathrm{CNPq}$ for the grant of a fellowship. The authors thank Dr. Y. Kawano for the helpful discussion.

\section{REFERENCES}

1. Y. Furukawa, A. Sakamoto, H. Ohta, and M. Tasumi, Synth. Met., 41, 1389 (1991).

2. H. Kuzmany, E. M. Genies, and A. Syed, in "Electronic Properties of Polymers and Related Compounds," H. Kuzmany, M. Mehring, and S. Roth, Ed., Springer Series in Solid State Science Vol. 63, Springer, Berlin, 1985, p 223.

3. Y. Furukawa, F. Ueda, Y. Hyodo, I. Harada, T. Nakajima, and T. Kawagoe, Macromolecules, 21, 1297 (1988).

4. N. S. Sariciftci. A. J. Heeger, V. Krasevec, P. Venturini, D. Mihailovic, Y. Cao, J. Libert, and J. L. Brédas, Synth. Met., 62, 107 (1994).

5. G. Louarn, M. Lapakowski, S. Quillard, A. Pron, J. P. Buisson, and S. Lefrant, J. Phys. Chem., 100, 6998 (1996).

6. J. Guay, M. Leclerc, and L. H. Dao, J. Electroanal. Chem., 31, 251 (1988).

7. A. Bingham and B. Ellis, J. Polym. Sci. A-1, 7, 3229 (1969).

8. A. A. Berhin, A. A. Ivanov, and I. I. Mirotvortsev, J. Polym. Sci., Polym. Symp., 40, 175 (1973).

9. U. Hayat, P. N. Bartlett, G. H. Dodd, and J. Barker, J. Electroanal. Chem., 220, 287 (1987).

10. N. Comisso, S. Daolio, G. Mengoli, R. Salmaso, S. Zecchin, and G. Zotti, J. Electroanal. Chem., 225, 97 (1988).

11. J. Guay and L. H. Dao, J. Electroanal. Chem., 274, 135 (1989).

12. J. Guay, R. Paynter, and L. H. Dao, Macromolecules, 23, 3598 (1990).

13. H. S. O. Chan, S. C. Ng, L. S. Leong, and K. L. Tan, Synth. Met., 68, 199 (1995).

14. H. de Santana, M. L. A. Temperini, and J. C. Rubim, J. Electroanal. Chem., 356, 145 (1993).

15. M. L. A. Temperini, in "Espectroscopia Raman: Princípio e Aplicações," O. Sala, D. Bassi, P. S. Santos, Y. Hase, R.I.M.G Forneris, M.L.A. Temperini, and Y. Kawano, Ed., Fund. Valeparaibana de Ensino. S. José dos Campos, São Paulo, 1984, p 188.

16. J. L. Brédas, J. C. Scott, K. Yakushi, and G. B. Street, Phys. Rev. B, 30, 1023 (1984).

17. W. S. Huang and A. G. MacDiarmid, Polymer, 34, 1833 (1983).

18. M. Lapkowski, K. Berrada, S. Quillard, G. Louarn, S. Lefrant, and A. Pron, Macromolecules, 28, 1233 (1995).

19. S. Stafsrom, J. L. Brédas, A. J. Epstein, H. S. Woo, D. B. Tanner, W. S. Huang, and A. G. MacDiarmid, Phys. Rev. Lett., 59, 1464 (1987).

20. A. Sakamoto, Y. Furukawa, and M. Tasumi, J. Phys. Chem., 96, 3870 (1992). 